\title{
Patients' attitudes and perceptions regarding research and their rights: a pilot survey study from the Middle East
}

Tamer Hifnawy, ${ }^{1,2}$ Samer Kobrosly, ${ }^{3}$ Hillary Edwards, ${ }^{4}$ Manal Anwar, ${ }^{2}$ Dalia Zahran ${ }^{1,5}$ and Henry Silverman ${ }^{4}$

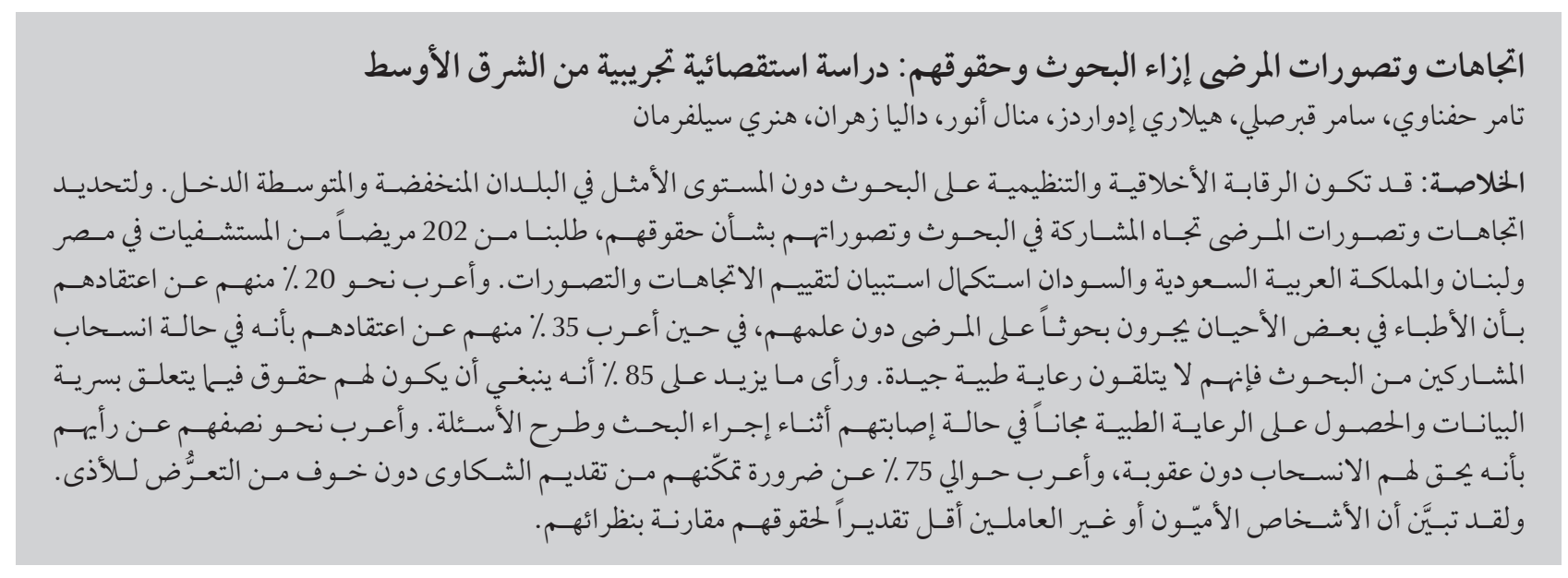

ABSTRACT Ethical and regulatory oversight of research may be suboptimal in low- and middle-income countries. To determine patients' attitudes and perceptions toward research participation and perceptions of their rights, we recruited 202 participants from hospitals in Egypt, Lebanon, Saudi Arabia and Sudan and asked them to complete a questionnaire assessing attitudes and perceptions. Around $20 \%$ believed that doctors sometimes perform research on patients without their knowledge and 35\% believed that if participants withdrew from the research they would not receive good medical care. Over $85 \%$ believed that they should have rights regarding confidentiality of data, free medical care if injured during the research and asking questions. Almost half believed they have a right to withdraw without penalty and around $75 \%$ believed they could make complaints without fear of harm. Those who were illiterate or unemployed were less likely to appreciate their rights compared with their counterparts.

Attitudes et perceptions des patients à l'égard de la recherche et de leurs droits : étude pilote au Moyen-Orient

RESUME La surveillance éthique et réglementaire de la recherche peut ne pas être optimale dans les pays à revenu faible et intermédiaire. Afin de déterminer les attitudes et les perceptions des patients à l'égard de la participation à la recherche et des perceptions de leurs droits, nous avons recruté 202 participants dans des hôpitaux en Arabie saoudite, en Égypte, au Liban et au Soudan, et leur avons demandé de compléter un questionnaire évaluant leurs attitudes et perceptions à ce sujet. Environ 20 \% croyaient qu'il arrivait que des médecins mènent des recherches sur des patients sans leur consentement, et $35 \%$ pensaient que si les participants se retiraient du processus de recherche, ils ne bénéficieraient pas de soins médicaux de qualité. Plus de 85 \% pensaient qu'ils devaient avoir droit à la confidentialité de leurs données, à des soins médicaux gratuits en cas d'incident durant la recherche et qu'ils devaient pouvoir poser des questions. Près de la moitié étaient d'avis qu'ils avaient le droit de se retirer de la recherche sans être pénalisés, et environ 75 \% pensaient qu'ils pouvaient adresser des plaintes sans craindre de subir des préjudices. Les participants illettrés ou sans emploi étaient moins susceptibles d'évaluer leurs droits que les autres participants. 


\section{Introduction}

The number of clinical trials conducted in low- and middle-income countries has increased worldwide (1), including the Middle East (2). Despite growing political volatility, the Middle East is poised for an escalation in the numbers of clinical trials as pharmaceutical companies continue their search for regions with large, treatment naive populations (3). Since medical research involves human subjects, knowledge regarding their attitudes and perceptions vis-à-vis research would help with understanding and addressing their concerns, which would enhance the overall trust between the public and the scientific community. Studies eliciting the views of patients on medical research have been performed in the United States, Denmark, Australia, and Japan (4-7), however these results might not be generalizable to low- and middle-income countries that may have different cultures, religions and economic backgrounds. Currently, there is limited empirical research involving the perspectives of patients from the Middle East (8-13). Additional studies would help with clarifying further the underlying assumptions of patients regarding their participation in research.

Another issue that warrants further investigation is the extent to which potential research participants are aware of and understand their rights in the research process. Although adherence to research ethics principles and guidelines help protect the welfare and the rights of research participants and their communities (14-16), commentators have expressed concerns regarding the regulatory framework (17), the functionality of research ethics committees (18), and the training of the research team regarding responsible research conduct (19) in low- and middle-income countries, including the Middle East. Such concerns make clear that research participants' realization of their rights provides them with a mechanism to protect their interests and prevent potential exploitation.

The concept of rights in research first developed after World War II in response to the practices of Nazi physicians who had experimented on unwilling subjects. The first international instrument on the ethics of medical research, the Nuremberg Code of 1947, was a direct outcome of these unethical practices, and it emphasized that the voluntary consent is "absolutely essential" and that "the human subject should be at liberty to bring the experiment to an end", i.e. a right to withdraw (20, 21). Since the Nuremberg Code, other international instruments have emphasized either directly or indirectly the existence of human rights in biomedical research, e.g. the Declaration of Helsinki in 1964, which has since undergone multiple revisions (17), the United $\mathrm{Na}$ tions' International Covenant on Civil and Political Rights (1966) (22) the Council of Europe's "The Convention for the Protection of Human Rights and Dignity of the Human Being with regard to the Application of Biology and Medicine: Convention on Human Rights and Biomedicine" (1997) (23) and in 2005, the "Additional Protocol to the Convention on Human Rights and Biomedicine, concerning Biomedical Research" (24). These documents make clear that the rights in research ethics are linked to ethics guidelines and governmental regulations, and emanate from fundamental ethical principles.

The use of "rights" language can help apply the general ethical principles in research. For example, to secure autonomy investigators need to disclose adequate information to potential research participants and ensure their understanding (i.e. the doctrine of informed consent). Other rights include the right to privacy and confidentiality and the right to medical treatment for any trial-related injury. The corresponding obligations on investigators and sponsors that help secure these rights include mechanisms to respect privacy, measures to enhance confidentiality protections, and the requirement to obtain indemnity insurance for researchrelated injuries.

Several studies have investigated the awareness of patients regarding their rights in clinical care in non-Western countries (25-34), but there are limited data regarding the perceptions of research participants regarding their rights (13). Accordingly, this study aimed to identify attitudes and perceptions towards research participation and awareness and understanding of the rights of potential participants from several countries in the Middle East: Egypt, Lebanon, Saudi Arabia and Sudan.

\section{Methods}

\section{Survey tool}

We developed a survey which contained the following sections: demographic information that included age, sex, education level, employment type and hospital type; attitudes and perceptions toward aspects of research participation; the extent of agreement to receive certain types of information necessary to decide upon participation in research; and the extent of agreement with certain rights in research. Questions required either a single/multiple response or were in the form of a 5-point Likert scale (strongly agree, agree, uncertain, disagree, strongly disagree).

Participants were also asked to respond to the following case study:

Rebekah comes to the clinic to have her blood drawn for routine laboratory examination. The investigator withdraws a little more than usual for research purposes. Which of the following are true?

- The investigator does not have to tell Rebekah the purpose of taking more blood.

- The investigator does not have to tell Rebekah whether the blood will be used in research. 
- The investigator should have asked for permission and informed consent from Rebekah

- It is expected that patients participate in research without patients' knowledge

If Rebekah suspects that the blood will be used in research, she can do which of the following:

- Ask the investigator to withdraw this sample

- Complain to the hospital director

- Submit a complaint to the medical syndicate or the organization giving the license

- Call the police

- Go to court

- Tell her family members, colleagues and friends not to go to this doctor

- Tell the media in order to warn the public from dealing with this doctor and this clinic

- Do nothing as nothing will be done about it

The survey was developed in English and then translated into Arabic followed by a back-translation into English to ensure accuracy of the Arabic translation. We pilot tested the survey among several lay persons to assess readability and understanding. Several changes were made in response to this assessment. Reliability of the questionnaire was calculated using the Cronbach $a$ test for internal consistency. Reliability of the questionnaire was judged by the internal consistency coefficient (Cronbach $\alpha$ ) of the 29 items using a 5 point Likert scale; this was 0.901 , indicative of a good degree of internal consistency.

\section{Participants}

Trained coordinators recruited participants from several sites at university and private-affiliated hospital outpatient clinics at the following locations: Beni Suef, Egypt; Beirut, Lebanon; Medina, Saudi Arabia; and Khartoum, Sudan. We used a convenience sampling technique with a target recruitment of 50 participants per site. The only inclusion criterion was age above 18 years. Participants were recruited during January and June 2014. The questionnaire was self-administered, however, for those who could not read or write, a study team member helped these individuals by reading and explaining each questions and the possible answers.

\section{Statistical analysis}

We entered the data into a Microsoft Excel coded file and transformed the data to SPSS, version 22. We used descriptive analysis and chi-squared analysis to determine the strength of the association of each of the independent variables (sex, education levels, and employment type) with each of the responses. Statistical differences within the sex, education and employment subgroups were determined using the Fisher's exact test. We set the significance level at $\mathrm{P}$-value $<0.05$.

To enhance our analyses, we collapsed the independent variables into the following subgroups. <list>

- Education: illiterate, high school or less, greater than high school

- Employment status: unemployed, manual worker/merchant, professional.
To improve the power, we collapsed the Likert scale responses of "strongly agree" and "agree" into one category; and the combination of "uncertain", "disagree" and "strongly disagree" into another category.

\section{Ethics review}

We received ethics approval from the research ethics committees at: University of Maryland School of Medicine, Baltimore (United States); College of Dentistry, Taibah University (Saudi Arabia); Faculty of Medicine, Beni Suef University (Egypt); Makassed General Hospital (Lebanon); and the University of Medical Sciences and Technology (Sudan).

\section{Results}

We enrolled 202 participants, 51 each from Egypt and Sudan and 50 each from Saudi Arabia and Lebanon. Results were not significantly different between these countries and therefore, we aggregated the data into a single group. The mean age of the participants was 42.1 [standard deviation (SD) 15.6] years. Twenty-eight respondents (13.9\%) had participated in medical

Table 1 Demographic characteristics of the respondents of respondents from 4

Middle Eastern countries $(\boldsymbol{n}=\mathbf{2 0 2})$

\begin{tabular}{lcc}
\hline Characteristic & No. & $\%$ \\
Sex & & \\
$\quad$ Male & 94 & 46.5 \\
$\quad$ Female & 108 & 53.5 \\
Education & & \\
$\quad$ Illiterate & 19 & 9.4 \\
$\quad$ High school or less & 119 & 58.9 \\
$\quad$ Greater than high school (university-level) & 64 & 31.7 \\
Employment & & \\
$\quad$ Unemployed & 67 & 33.2 \\
$\quad$ Manual worker/merchant & 88 & 43.6 \\
$\quad$ Professional & 47 & 23.3 \\
Hospital type & & \\
$\quad$ Private & 50 & 24.8 \\
$\quad$ University & 152 & 75.2 \\
\hline
\end{tabular}


research, of whom 17 were currently enrolled in research. Responses from those with and those without experience in research were not significantly different and hence we only present the results of the entire study sample.

Table 1 shows the respondents' demographic data. There were an almost equal number of men and women participants (46.5\% and $54.5 \%$ respectively). Sixty-four (31.7\%) participants had an education level above high school. Approximately one-third were unemployed. The ratio of patients attending private and university hospital outpatient clinics was 1:3.

Table 2 shows respondents' attitudes toward medical research. Overall, 92.6\% believed that medical research was necessary to improve health within a society. Respondents held decreasing preferences for participation in the following types of research: questionnaire studies, blood sampling studies and drug trials $(87.1 \%, 64.4 \%$, and $44.6 \%$; respectively). The top 3 reasons for enrolling in research were: to help other patients (50.0\%), the belief that patients in research get better treatment (41.6\%) and the chance to get better care $(41.1 \%)$.

Around 20\% of respondents believed that doctors sometimes perform research on patients without their knowledge; individuals who were illiterate were more likely to hold this opinion compared with those in the 2 other education groups ( $42.1 \%$ vs. $22.7 \%$ and $10.9 \%$, respectively; $\mathrm{P}<0.01$ ) (Table 2 ). A little over a third of the respondents (35.0\%) believed that if research participants withdrew from the research they would not receive good medical care from their doctors.

Actions that respondents would take if they had have a complaint about the research included: complain to the investigators (41.0\%) and complain to the hospital director (28.8\%) (Table2).

In response to the case study regarding a clinic patient from whom a physician withdraws additional blood for research purposes, $80.5 \%$ believed that the investigator should have asked for the patient's informed consent for the additional blood (Table 2). Those who were unemployed were significantly less likely to believe that physicians should ask for consent from the patient compared with manual workers/ merchants and professionals $(68.2 \%$ vs $85.24 \%$ and $89.1 \%$, respectively; $P<$ $0.01)$.

When asked what the patient could do about the additional sample of blood that was withdrawn, the top choices included: ask the physician to withdraw the sample (51.0\%); complain to the hospital director (25.7\%); and one should do nothing as nothing would be done (22.3\%) (Table 2). Those who were illiterate were more likely to believe that "one should do nothing as nothing would be done" compared with those at a higher educational levels; (36.8\% vs. $25.2 \%$ and $12.5 \%$, respectively; $P<$ $0.05)$. Similarly, those who were unemployed were more likely to believe this compared with manual workers/ merchants and professionals $(31.3 \%$ vs. $20.5 \%$ and $12.8 \%$, respectively; $P<$ $0.05)$. Those who were unemployed were significantly less likely to ask the physician to withdraw the sample compared with those who were manual workers/merchants and professionals ( $37.3 \%$ vs. $53.4 \%$ and $66.0 \%$, respectively; $P<0.01)$. However, those who were unemployed or were manual workers/ merchants were more likely to complain to the hospital director compared with professionals ( $32.8 \%$ and $28.4 \%$ vs. $10.6 \%$, respectively, $P<0.05)$.

More than $75 \%$ of the respondents believed that, prior to enrolment in a study, research participants should be provided with all the information described in the questions (Table 3). More than $95 \%$ agreed that participants should be informed about the risks and side-effects and the anticipated benefits of the research.
At least $85 \%$ of the respondents believed that they should be told that enrolment in research is voluntary and that they have the right to have data kept confidential; have the right to receive free medical care if injured from the research; and have the right to ask questions about the study (Table 4). However, only $49 \%$ thought they should have a right to withdraw from the study.

Respondents who were unemployed were significantly less likely to believe that they should be told that enrolment is voluntary compared with manual workers/merchants and professionals $(80.0 \%$ vs. $92.0 \%$ and $97.9 \%$, respectively; $P<0.01)$. Individuals who were illiterate were significantly less likely to believe they could file a complaint compared with the other 2 education levels ( $57.9 \%$ vs. $70.1 \%$ and $87.5 \%$, respectively, $P<0.01$ ); they were significantly less likely to believe that research data should be kept secret from individuals not involved in research compared with the other 2 education levels ( $52.6 \%$ vs. $87.2 \%$ and $90.6 \%$, respectively); and they were also significantly less likely to believe they should have an opportunity to ask questions compared with the other two groups $(78.9 \%$ vs. $93.2 \%$ and $98.4 \%$, respectively, $P<0.01)$.

\section{Discussion}

This study reveals certain attitudes and perceptions of patients from the Middle East regarding research as well as their perceptions of their rights as research participants. In general, most of our participants expressed favourable attitudes towards research. For example, more than $90 \%$ believed that research was necessary to improve the health of society; similar findings regarding the importance of research have been reported in other studies from the Middle East $(9,13)$. We found that $50.0 \%$ of participants cited a desire to help others as a reason to enrol in research. 


\begin{tabular}{|c|c|c|}
\hline \multirow[t]{2}{*}{ Question } & \multicolumn{2}{|c|}{ Response $^{a}$} \\
\hline & No. & $\%$ \\
\hline Medical research is necessary to improve the health of society & 187 & 92.6 \\
\hline \multicolumn{3}{|l|}{ I would most likely volunteer to participate in the following types of trials ${ }^{a}$ : } \\
\hline Questionnaire studies & 176 & 87.1 \\
\hline Blood sampling studies & 130 & 64.4 \\
\hline Drug trialst & 90 & 44.6 \\
\hline \multicolumn{3}{|l|}{ Why would you volunteer to participate in research? ${ }^{b}$} \\
\hline Help other patients & 101 & 50.0 \\
\hline Patients in research receive better treatment than those not in researcha & 84 & 41.6 \\
\hline Chance to get better care & 83 & 41.1 \\
\hline $\begin{array}{l}\text { Participants who withdraw from the research will not receive good medical care from their } \\
\text { doctors }^{\mathrm{a}}\end{array}$ & 70 & 35.0 \\
\hline Get extra attention & 62 & 30.7 \\
\hline My doctor sometimes performs research on me without my knowledgea & 42 & 20.8 \\
\hline Only way to get hospital care & 18 & 8.9 \\
\hline Monetary incentives & 15 & 7.4 \\
\hline \multicolumn{3}{|l|}{ Actions that participants could take if they have complaints about the researchc $(n=156)$} \\
\hline Complain to the investigators & 64 & 41.0 \\
\hline Complain to the hospital director & 45 & 28.8 \\
\hline No need to complain, nothing will be done & 37 & 25.4 \\
\hline Put a paper in the complaint box & 24 & 15.4 \\
\hline Complain to the research ethics committee & 14 & 9.0 \\
\hline \multicolumn{3}{|l|}{ Case of patient from whom physician withdraws additional blood sample for research ${ }^{c}$} \\
\hline \multicolumn{3}{|l|}{ Which of the following is true? } \\
\hline Physicians should ask for consent from the patient & 161 & 80.5 \\
\hline Physicians do not need to reveal the purpose of the additional blood sample & 19 & 9.4 \\
\hline Other response & 20 & 9.9 \\
\hline \multicolumn{3}{|l|}{ What can the patient do if she suspects that the additional blood will be used in research? } \\
\hline Ask the physician to withdraw the sample & 103 & 51.0 \\
\hline Complain to the hospital director & 52 & 25.7 \\
\hline Do nothing as nothing will be done & 45 & 22.3 \\
\hline Tell others not to see this doctor/tell the media & 28 & 13.9 \\
\hline Complain to the physician's board & 15 & 7.4 \\
\hline Call the police or go to court & 8 & 4.0 \\
\hline
\end{tabular}

apercentage of those who strongly agreed or agreed.

${ }^{b}$ Check all that apply.

${ }^{c}$ Choose one best answer.

This, however, contrasts with other studies showing that more than $90 \%$ stated a similar reason $(9,12,13)$. Also, the chance to get better treatment was cited by only $41.1 \%$ of our respondents as a reason to participate in research. In contrast, a recent study in Saudi Arabia reported that $80.4 \%$ of their respondents stated that "receiving best medical care" was a motivation to enrol in clinical trials (13), and in an Egyptian study $100 \%$ of the participants who were enrolled in clinical trials were motivated to receive a "chance to get better treatment" (9). These 2 studies were focused on motivations for enrolling in clinical trials, which have potential direct benefits to participants, whereas our survey asked respondents for their reasons for enrolling in research that also included blood sampling and questionnaire studies; this might explain why fewer of our participants cited better treatment/care as a motivation.

Most respondents said they would participate in questionnaire studies, while significantly fewer would participate in studies involving blood sampling and drugs. Khalil et al. observed similar findings in their qualitative, in-depth 


\begin{tabular}{|c|c|c|}
\hline \multirow[t]{2}{*}{ Item } & \multicolumn{2}{|c|}{ Response $^{a}$} \\
\hline & No. & No. \\
\hline Participants should know the risks and side-effects of the research & 197 & 98.5 \\
\hline Participants should be given an explanation of anticipated benefits from the research & 191 & 95.5 \\
\hline Participants should be given an explanation of the procedures and any drugs that will be used & 181 & 90.0 \\
\hline Participants should be told that enrolment in research is voluntary & 179 & 89.5 \\
\hline Participants should know the purpose of the research & 177 & 88.1 \\
\hline $\begin{array}{l}\text { Patients should be provided with contact information if questions, concerns, or complaints about the } \\
\text { research were to occur }\end{array}$ & 176 & 88.0 \\
\hline Participants should know the alternatives of medical treatment they can receive outside of the study & 157 & 78.9 \\
\hline
\end{tabular}

apercentage of those who strongly agreed or agreed.

interview study in Egypt regarding preferences for participation in types of research, and attributed their findings to the increasing risk associated with questionnaire, blood sample and drug trials respectively (8).

Our respondents held several problematic perceptions. For example, around one-fifth believed that research is performed on them without their knowledge and more than a third that they would not get good medical care if they withdrew from the study. In a study involving Saudi Arabian patients and their companions from the outpatient clinics of a tertiary hospital, Al-Tannir et al. reported that only $48.7 \%$ of their respondents believed that research was conducted in a responsible and ethical manner, which led the authors to conclude that potential participants held "conditional" attitudes towards participating in clinical trials and that investigators need to provide assurances to potential research participants that all necessary procedures would be used to enhance their welfare and rights (13). Our findings also support this proposition.

Our study also demonstrated that a significant minority of respondents had a sense of futility if they had a complaint about a research study as $25.4 \%$ believed that nothing would be done if they complained. A similar proportion (22.3\%) held a comparable attitude regarding the uselessness of filing a complaint in the case study we used in the questionnaire. This concern that no-one would respond to their complaints harmonizes with our finding that $74.5 \%$ of our respondents believed that research participants should have a right to make a complaint against any member of the research team without a fear of retribution.

Many of our participants also expressed awareness in regard to other research rights. For example, over $85 \%$ believed that there should be protection for confidentiality, compensation for research-related injury, the ability to ask questions about the research study and that they should be told that participation was voluntary. Indirectly, our respondents also believed in the right to informed consent as, when responding to the case study, a large majority believed that there was a requirement for the physician to obtain informed consent from the patient for the additional blood sample being obtained for research.

In contrast, just under half of our respondents believed they had a right to withdraw from the study without giving any reason. This perception might be due to potential concerns with retribution after withdrawal, as $35 \%$ also believed that participants who withdrew from the research would not receive good medical care from their doctors. In a study involving Saudi Arabian patients and their companions, it was reported that only $59.5 \%$ of the respondents were aware of their right to withdraw from a clinical trial at any time without consequences (13).

Our data showed that individuals who might be vulnerable in research, e.g. those who are illiterate or unemployed, were less sure of their rights. For example, compared with individuals at a higher level of education, those who were illiterate were significantly less likely to believe that research participants should have rights regarding confidentiality, filing a complaint against the research team and having the opportunity to ask questions. Those who were unemployed were significantly less likely to believe that physicians should obtain informed consent for obtaining an additional blood sample for research purposes, and less likely to believe that they should be told that participation in research was voluntary. These findings regarding vulnerable individuals (i.e. those less able to protect their interests) may be a result of their being unaware of their rights and less optimistic that such rights can be realized, or a concern that retribution would occur if they insist on their rights.

Although studies investigating perceptions of potential research participants' regarding their rights are limited, several studies from low- and middleincome countries have explored the awareness of patients regarding their rights in medical care. These studies 


\begin{tabular}{|c|c|c|}
\hline \multirow[t]{2}{*}{ Item } & \multicolumn{2}{|c|}{ Response $^{\mathrm{a}}$} \\
\hline & No. & $\%$ \\
\hline Participants should be given the opportunity to ask questions about the study & 187 & 93.5 \\
\hline If participants become injured, then they should receive free medical care & 182 & 91.0 \\
\hline Participants should be told that enrolment in research is voluntary & 179 & 89.5 \\
\hline The data obtained from participants should be kept secret from individuals not involved in the research & 170 & 85.0 \\
\hline Participants should be given a copy of the informed consent form & 153 & 76.5 \\
\hline $\begin{array}{l}\text { Participants should be able to make a complaint against any member of the research team without fear of } \\
\text { being harmed }\end{array}$ & 149 & 74.5 \\
\hline Participants should be provided with monies to reimburse for the costs of travel & 116 & 58.6 \\
\hline Participants in clinical research should be allowed to withdraw from the study without giving any reason & 98 & 49.0 \\
\hline Participants should be able to receive money for their efforts that is above reimbursements & 92 & 46.2 \\
\hline
\end{tabular}

aPercentage of those who strongly agreed or agreed.

demonstrate a wide range of variability. For example, studies demonstrating that patients have a low awareness of their rights included those from Turkey (23\%) (25), Greece (15.7\%) (26), Egypt (23.3\%) (31), and Saudi Arabia (25\%) (29). In contrast, higher rates of awareness were demonstrated among patients in Lithuania (56\%) (27), Poland (80\%) (30), Malaysia (90\%) (28), and Nigeria (94.2\%) (33).

In a study involving patients in Greece, $25.7 \%$ would do nothing if their rights were being violated (26) and in another study involving patients attending outpatient clinics in Nigeria, 25\% would not seek redress if their rights were violated (33). These results are similar to our data showing that approximately $25 \%$ of respondents would not file a complaint as they thought that nothing would be done in response. However, in the study in Egypt, a higher proportion of the patients or their companions (approximately 60\%) would "do nothing" when facing problems or harm in the hospital (31). This higher result might be due to their sample population, almost half of whom were illiterate, as opposed to only $9 \%$ in our sample, indicating that illiteracy might be a surrogate marker for vulnerability.

There were several limitations to our study. First, we used a convenience sampling method for recruitment and our site coordinators reported that some potential respondents did not want to participate due to their uncertainty regarding the informed consent process. This selection bias might have affected the validity of our results. Also, our sample size might not have been large enough to detect other significant findings. Future studies should employ a larger sample size and enrol individuals from additional centres in the region to enhance the generalizability of our results. Finally, the conduct of research in the Middle East is limited compared with other regions in the world (3), and hence, several of the troubling perceptions expressed by our study population might not reflect how research is actually conducted and the level of safeguards associated with research that provide protection of their welfare and rights in research. Consequently, perceptions might differ from those who have participated in research (9). Nonetheless, the perceptions held by our study sample may represent major limiting factors for recruitment for research and impair trust in the research endeavour and hence, need to be addressed.

Regarding a research agenda, we recommend additional studies regarding perception of rights in research in other countries in the Middle East to validate our findings and to further explore in-depth the potential role of independent factors (e.g. education, poverty) that might be associated with potential research participants' awareness of rights and the likelihood that they will make a claim on their rights. Such studies should also include those currently enrolled in research studies. Furthermore, we recommend the use of qualitative studies (semi-structured interviews, focus groups) to further explore the explanatory mechanisms that promote awareness and realization of rights.

Regarding best practices, we recommend that members of the research team take affirmative action to provide assurances to potential participants that all necessary steps will be taken to protect their rights and welfare. Investigators and other members of the research staff should also serve as the critical link to informing participants in research about their rights. Optimizing practices regarding rights in research can help enhance and maintain trust in the research endeavour.

\section{Funding: None.}

Competing interests: None declared. 
1. Glickman SW, McHutchison JG, Peterson ED, Cairns CB, Harrington RA, Califf RM, et al. Ethical and scientific implications of the globalization of clinical research. N Engl J Med. 2009;360:816-23. PMID:19228627

2. Normile D. The promise and pitfalls of clinical trials overseas. Science. 2008;322(5899):214-6. PMID:18845744

3. Misik V. Middle East region poised for clinical trials growth. CenterWatch News Online 2011 (http://www.centerwatch. $\mathrm{com} /$ news-online/article/2396/middle-east-region-poisedfor-clinical-trials-growth\#sthash.a22jTG8r.dpbs, accessed, 1 April 2017) .

4. Sugarman J, Kass NE, Goodman SN, Perentesis P, Fernandes $P$, Faden RR. What patients say about medical research. IRB. 1998;20(4):1-7. PMID:11657084

5. Madsen SM, Mirza MR, Holm S, Hilsted KL, Kampmann K, Riis P. Attitudes towards clinical research amongst participants and nonparticipants. J Intern Med. 2002;251(2):156-68. PMID:11905591

6. Ellis PM, Butow PN. Focus group interviews examining attitudes to randomised trials among breast cancer patients and the general community. Aust NZ J Public Health. 1998;22(5):52831. PMID:9744203

7. Asai A, Ohnishi M, Nishigaki E, Sekimoto M, Fukuhara S, Fukui T. Focus group interviews examining attitudes towards medical research among the Japanese: a qualitative study. Bioethics. 2004;18(5):448-70. PMID:15462026

8. Khalil SS, Silverman HJ, Raafat M, El-Kamary S, El-Setouhy M. Attitudes, understanding, and concerns regarding medical research amongst Egyptians: a qualitative pilot study. BMC Med Ethics. 2007;8:9. PMID:17727728

9. Mansour H, Zaki N, Abdelhai R, Sabry N, Silverman H, ElKamary SS. Investigating the informed consent process, therapeutic misconception and motivations of Egyptian research participants: a qualitative pilot study. East Mediterr Health J. 2015;21(3):155-63. PMID:26074215

10. Nabulsi M, Khalil Y, Makhoul J. Parental attitudes towards and perceptions of their children's participation in clinical research: a developing-country perspective. J Med Ethics. 2011;37(7):420-3. PMID:20713534

11. Al-Qadire MM, Hammami MM, Abdulhameed HM, Al Gaai EA. Saudi views on consenting for research on medical records and leftover tissue samples. BMC Med Ethics. 2010;11:18. PMID:20955580

12. Al-Amad S, Awad M, Silverman H. Attitudes of dental patients towards participation in research. East Mediterr Health J. 2014;20:(2)90-8. PMID:24945557

13. Al-Tannir MA, El-Bakri N, Abu-Shaheen AK. Knowledge, attitudes and perceptions of Saudis towards participating in clinical trials. PLoS One. 2016;11(2):e0143893. PMID:26848750

14. Ahmad K. Developing countries need effective ethics review committees. Lancet. 2003;362(9384):627. PMID:12947948

15. Bhutta AZ. Ethics in international health research: a perspective from the developing world. Bull World Health Organ. 2002;80(2):114-20. PMID:11953789

16. Hyder AA, Wali SA, Khan AN, Teoh NB, Kass NE, Dawson L. Ethical review of health research: a perspective from developing country researchers. J Med Ethics. 2004;30(1):68-72. PMID:14872079

17. Alahmad G, Al-Jumah M, Dierickx K. Review of national research ethics regulations and guidelines in Middle Eastern Arab countries. BMC Med Ethics. 2012;13:34. PMID:23234422

18. Sleem H, Moodley K, Kumar N, Moni M, Naidoo S, Silverman $\mathrm{H}$. Self-assessment of the operations and functions of research ethics committees in developing countries. Rotterdam, Netherlands: International Association of Bioethics; 2012.

19. Ana J, Koehlmoos T, Smith R, Yan LL. Research misconduct in low- and middle-income countries. PLoS Med. 2013;10(3):e1001315. PMID:23555197

20. Annas GJ, Grodin MA. Reflections on the fiftieth anniversary of the Doctors' Trial. Health Hum Rights 1996;2(1):7-21. PMID:11657276

21. Nuremberg Code. Trials of war criminals before the Nuremberg military tribunals under Control Council Law No. 10. Washington, DC: US Government Printing Office; 1949.

22. International Covenant on Civil and Political Rights. Geneva: United Nations Human Rights, Office of the High Commissioner; 1966 (http://www.ohchr.org/EN/Professionallnterest/Pages/CCPR.aspx, accessed 1 April 2017).

23. Convention for the protection of human rights and dignity of the human being with regard to the application of biology and medicine: convention on human rights and biomedicine. Strasbourg: Council of Europe; 1997 (http://www.coe.int/ en/web/conventions/full-list/-/conventions/treaty/164, accessed 1 April 2016)

24. Additional protocol to the convention on human rights and biomedicine, concerning biomedical research. Strasbourg: Council of Europe; 2005 (https://rm.coe.int/CoERMPublicCommonSearchServices/DisplayDCTMContent?documentld $=090000168008371 \mathrm{a}$, accessed 1 April 2016).

25. Zulfikar F, Ulusoy MF. Are patients aware of their rights? A Turkish study. Nurs Ethics. 2001;8(6):487-98. PMID:16004104

26. Merakou K, Dalla-Vorgia P, Garanis-Papadatos T, Kourea-Kremastinou J. Satisfying patients' rights: a hospital patient survey. Nurs Ethics. 2001;8(6):499-509. PMID:16004105

27. Ducinskiene D, Vladickiene J, Kalediene R, Haapala I. Awareness and practice of patient's rights law in Lithuania. BMC Int Health Hum Rights. 2006;6:10.

28. Yousuf RM, Fauzi AR, How SH, Akter SF, Shah A. Hospitalised patients' awareness of their rights: a cross-sectional survey from a tertiary care hospital on the east coast of Peninsular Malaysia. Singapore Med J. 2009;50(5):494-9. PMID:19495519

29. Alghanim SA. Assessing knowledge of the patient bill of rights in central Saudi Arabia: a survey of primary health care providers and recipients. Ann Saudi Med. 2012;32(2):151-5. PMID:22366828

30. Krzych LJ, Ratajczyk D. Awareness of the patients' rights by subjects on admission to a tertiary university hospital in Poland. J Forensic Leg Med. 2013;20(7):902-5. PMID:24112342

31. Abou Zeina HA, El Nouman AA, Zayed MA, Hifnawy T, El Shabrawy EM, El Tahlawy E. Patients' rights: a hospital survey in South Egypt. J Empir Res Hum Res Ethics. 2013;8(3):46-52. PMID:23933775

32. Mastaneh Z, Mouseli L. Patients' awareness of their rights: insight from a developing country. Int J Health Policy Manag. 2013;1(2):143-6. PMID:24596854

33. Abolarin IO, Oyetunde MO. Patients' knowledge and exercise of their rights at the University College Hospital, Ibadan. Afr J Med Med Sci. 2013;42(3):253-60. PMID:24579387

34. Yaghobian M, Kaheni S, Danesh M, Rezayi Abhari F. Association between awareness of patient rights and patient's education, seeing bill, and age: a cross-sectional study. Glob J Health Sci. 2014;6(3):55-64. PMID:24762346 